Delft University of Technology

\title{
Self healing of creep damage in iron-based alloys by supersaturated tungsten
}

Fang, H.; Szymanski, N.; Versteylen, C. D.; Cloetens, P.; Kwakernaak, C.; Sloof, W. G.; Tichelaar, F. D.; Balachandran, S.; Herbig, M.; Brück, E.

DOI

10.1016/j.actamat.2019.01.014

Publication date

2019

Document Version

Final published version

Published in

Acta Materialia

\section{Citation (APA)}

Fang, H., Szymanski, N., Versteylen, C. D., Cloetens, P., Kwakernaak, C., Sloof, W. G., Tichelaar, F. D., Balachandran, S., Herbig, M., Brück, E., van der Zwaag, S., \& van Dijk, N. H. (2019). Self healing of creep damage in iron-based alloys by supersaturated tungsten. Acta Materialia, 166, 531-542.

https://doi.org/10.1016/j.actamat.2019.01.014

Important note

To cite this publication, please use the final published version (if applicable).

Please check the document version above.

\section{Copyright}

Other than for strictly personal use, it is not permitted to download, forward or distribute the text or part of it, without the consent of the author(s) and/or copyright holder(s), unless the work is under an open content license such as Creative Commons.

\section{Takedown policy}

Please contact us and provide details if you believe this document breaches copyrights.

We will remove access to the work immediately and investigate your claim. 
Green Open Access added to TU Delft Institutional Repository 'You share, we take care!' - Taverne project

\section{https://www.openaccess.nl/en/you-share-we-take-care}

Otherwise as indicated in the copyright section: the publisher is the copyright holder of this work and the author uses the Dutch legislation to make this work public. 
Full length article

\title{
Self healing of creep damage in iron-based alloys by supersaturated tungsten
}

\author{
H. Fang ${ }^{\text {a, b }}$, N. Szymanski a , C.D. Versteylen ${ }^{\text {a }}$, P. Cloetens ${ }^{\text {c }}$, C. Kwakernaak ${ }^{\text {d }}$, W.G. Sloof ${ }^{\text {d }}$, \\ F.D. Tichelaar ${ }^{\text {e }}$, S. Balachandran ${ }^{\text {f }}$, M. Herbig ${ }^{\text {f }}$, E. Brück ${ }^{\text {a }}$, S. van der Zwaag ${ }^{\text {b, g, }}$, \\ N.H. van Dijk ${ }^{\text {a, * }}$ \\ ${ }^{a}$ Fundamental Aspects of Materials and Energy Group, Faculty of Applied Sciences, Delft University of Technology, Mekelweg 15, 2629 JB, Delft, the \\ Netherlands \\ ${ }^{\mathrm{b}}$ Novel Aerospace Materials Group, Faculty of Aerospace Engineering, Delft University of Technology, Kluyverweg 1, 2629 HS, Delft, the Netherlands \\ ${ }^{\mathrm{c}}$ European Synchrotron Radiation Facility, 38043, Grenoble Cedex 9, France \\ d Department of Materials Science and Engineering, Delft University of Technology, Mekelweg 2, 2628 CD, Delft, the Netherlands \\ e Kavli Institute of Nanoscience, National Centre for HREM, Delft University of Technology, Lorentzweg 1, 2628 CJ, Delft, the Netherlands \\ ${ }^{\mathrm{f}}$ Max-Planck-Institut für Eisenforschung GmbH, Max-Planck-Straße 1, 40237, Düsseldorf, Germany \\ ${ }^{\mathrm{g}}$ School of Materials Science and Engineering, Tsinghua University, Beijing, 100084, China
}

\section{A R T I C L E I N F O}

\section{Article history:}

Received 31 October 2018

Received in revised form

8 January 2019

Accepted 10 January 2019

Available online 11 January 2019

\section{Keywords:}

Self-healing

Creep damage

Synchrotron radiation

Tomography

Steel

\begin{abstract}
A B S T R A C T
When metals are mechanically loaded at elevated temperatures for extended periods of time, creep damage will occur in the form of cavities at grain boundaries. In the present experiments it is demonstrated that in binary iron-tungsten alloys creep damage can be self healed by selective precipitation of a W-rich phase inside these cavities. Using synchrotron X-ray nano-tomography the simultaneous evolution of creep cavitation and precipitation is visualized in 3D images with a resolution down to $30 \mathrm{~nm}$. The degree of filling by precipitation is analysed for a large collection of individual creep cavities. Two clearly different types of behaviour are observed for isolated and linked cavities, where the isolated cavities can be filled completely, while the linked cavities continue to grow. The demonstrated selfhealing potential of tungsten in iron-based metal alloys provides a new perspective on the role of $\mathrm{W}$ in high-temperature creep-resistant steels.
\end{abstract}

๑) 2019 Acta Materialia Inc. Published by Elsevier Ltd. All rights reserved.

\section{Introduction}

Steels are among the most developed engineering materials in current society for their excellent performance under a wide variety of demanding conditions. However, when steels are exposed to temperatures above $450^{\circ} \mathrm{C}$ in the presence of a mechanical load creep damage generally develops. Under these conditions the formation of isolated grain-boundary cavities, followed by their coalescence, ultimately leads to the formation of a catastrophic crack. To improve the creep resistance, and thereby prolong the creep lifetime of steel components subjected to external stress and high temperature, abundant efforts have been made to optimize the

\footnotetext{
* Corresponding author. Delft University of Technology, Faculty of Applied Sciences, Department of Radiation Science and Technology, Fundamental Aspects of Materials and Energy group, Mekelweg 15, 2629 JB, Delft, the Netherlands.

E-mail address: n.h.vandijk@tudelft.nl (N.H. van Dijk).
}

chemical composition and the microstructure by combining solidsolution strengthening, precipitation hardening and work hardening as strengthening routes to increase the initial strength and reduce the rate of damage formation as much as possible [1-5]. However, once a creep cavity nucleates at a load-bearing grain boundary, its growth cannot be stopped and coalescence with neighbouring cavities eventually leads to failure.

Recently, a novel approach was proposed in which the creep damage is healed by the material itself, resulting in a significant prolongation of the lifetime [6-8]. For austenitic stainless steels Laha and coworkers [9-11] and Shinya [12] observed that the precipitation of either $\mathrm{Cu}$ or $\mathrm{BN}$ at the creep cavity surface resulted in a significant increase in the creep lifetime. Subsequently, Zhang and coworkers [13-16] demonstrated that the creep cavities in FeAu and Fe-Mo alloys can be filled by second-phase precipitation driven by the diffusion of supersaturated solute atoms in the ferritic iron-rich matrix. Based on these studies on Fe-X binary alloys, the following key requirements for an efficient self healing of creep 
damage were identified: (i) the element $\mathrm{X}$ can be fully dissolved into the matrix at a high temperature and be brought to an adequate degree of supersaturation at the creep temperature to provide an appreciable driving force for precipitation; (ii) the atomic size of $\mathrm{X}$ is considerably larger than that of $\mathrm{Fe}$, resulting in a high nucleation barrier for precipitation in the matrix and a strong preference to precipitate at the free surface of the cavity; (iii) the diffusivity of element $X$ must be larger than that of Fe to ensure that the filling of the cavity (controlled by solute diffusion) can catch up with the cavity growth (controlled by vacancy diffusion).

Tungsten is highly appreciated as an important alloying element in high-performance creep-resistant steels, like high chromium (9-12 wt\% Cr) ferritic/martensitic steels, because of its excellent solid-solution strengthening and precipitation hardening. For the currently most advanced creep-resistant high-chromium steels, W is added to replace part of the Mo to improve the creep-resistance at higher temperatures and to reduce neutron activation for potential applications in Generation IV nuclear reactors [17-19]. Although a lot of work [20-24] has been done to study the effect of $\mathrm{W}$ on the creep properties, only the options of solid-solution strengthening and precipitation hardening have been investigated without considering the interaction of solute $\mathrm{W}$ with creep cavities leading to cavity filling by $(\mathrm{Fe}, \mathrm{Cr})_{2}(\mathrm{Mo}, \mathrm{W})$ Laves phase precipitates.

Tungsten satisfies the key requirements to be an efficient healing agent in Fe-based alloys due to the larger atomic radius $\left(r_{\mathrm{W}} /\right.$ $r_{\mathrm{Fe}} \approx 1.10$ ) and the larger solute diffusivity [25] compared to that of Fe in the ferritic iron-rich matrix. With an appropriate heat pretreatment even low concentrations of $\mathrm{W}$ can be turned into a supersaturated state at creep temperatures of $500-700^{\circ} \mathrm{C}$. In the present study it is demonstrated that supersaturated $\mathrm{W}$ can indeed act as an effective healing agent in Fe-W alloys by monitoring the filling of creep cavities by $\mathrm{Fe}_{2} \mathrm{~W}$ Laves phase precipitates as a function of the creep time. To this aim creep tests are performed on a solutionised $\mathrm{Fe}-(4 \mathrm{wt} \%) \mathrm{W}$ alloy for different constant loads at a temperature of $550{ }^{\circ} \mathrm{C}$. Synchrotron X-ray nano-tomography provides a powerful 3D imaging tool [26] to characterize the evolution of both the creep cavities and the precipitation inside these cavities at different stages of the creep life with a very high spatial resolution down to $30 \mathrm{~nm}$ (for an illustration of the technique see Fig. S1 in Supplementary Information).

\section{Experimental}

\subsection{Samples}

Rolled sheets of high-purity Fe-W binary alloy sample were produced by Goodfellow. The chemical composition of the Fe-W alloy is $3.800 \mathrm{wt} \% \mathrm{~W}, 0.020 \mathrm{wt} \% \mathrm{Si}, 0.026 \mathrm{wt} \% \mathrm{~S}, 0.0014 \mathrm{wt} \% \mathrm{~N}$, $0.0024 \mathrm{wt} \% \mathrm{C}$ and balance Fe. Dog-bone shaped creep test samples (with a gauge length of $12.5 \mathrm{~mm}$, a width of $6 \mathrm{~mm}$ and a thickness of $0.5 \mathrm{~mm}$ ) were cut from the as-received sheet material by spark erosion. These samples were then annealed at $900^{\circ} \mathrm{C}$ for $24 \mathrm{~h}$ in an evacuated and sealed quartz tube filled with 200 mbar ultra-high purity argon and subsequently quenched in water. Scanning electron microscopy was used to observe the quenched material and observations confirmed that the alloy was in a fully solutionised state and there were no grain-boundary precipitates in the samples after the heat treatment. The average grain diameter of the quenched samples was determined from the electron microscopy images and amounted to $127 \mu \mathrm{m}$. Creep tests were performed in vacuum on the solutionised alloy samples at a temperature of $550{ }^{\circ} \mathrm{C}$ and initial loads of 140 and $160 \mathrm{MPa}$.

\subsection{Creep tests}

Initial creep tests until sample rupture were carried out to determine the rupture time $t_{\mathrm{R}}$ for a specific creep condition (Fig. S2 in Supplementary Information). Based on these results, creep tests for the same creep condition were performed that were interrupted after a selected fraction of the expected rupture lifetime (e.g. $t /$ $t_{R}=0.25,0.50$ and 0.75 ). For the tomography experiments barshaped samples with a cross section of $250 \times 250 \mu \mathrm{m}^{2}$ and a length of about $6 \mathrm{~mm}$ were cut by spark erosion after the creep tests from the uniform gauge section of the dog-bone shaped creep samples. The long axis of the tomography samples was along the direction of the applied stress during creep testing.

\subsection{Scanning electron microscopy}

The 2D microstructure of the samples after creep was analysed by a scanning electron microscope (JEOL JSM 6500F). Except for the analysis of the fracture surface (Fig. S3 in Supplementary Information), the microstructure analysis was performed in the uniform elongation part of the samples. In the grain interior of the asreceived material a limited number of spherical $\mathrm{FeWO}_{4}$ precipitates were observed. Statistical results of SEM images for the asreceived samples indicate that the $\mathrm{FeWO}_{4}$ precipitates have an average radius of $0.4 \mu \mathrm{m}$ and occupy a volume fraction of $0.05 \%$ (containing $0.03 \mathrm{wt} \% \mathrm{~W}$ ). This indicates that about $1 \%$ of the nominal concentration of $\mathrm{W}$ is bound in the oxides. Given that the consumption of $\mathrm{W}$ by the formation of $\mathrm{FeWO}_{4}$ inclusions is very low and that these oxides are very stable and located in the grain interior, these particles are not expected to have affected Laves phase precipitation at free surface of the creep cavities.

\subsection{Transmission electron microscopy}

Transmission electron microscopy (TEM) measurements were performed using a Tecnai F20ST/STEM instrument operating at 200 kV. Bright Field (BF), lattice images (without objective aperture), and Annular Dark Field (ADF) in STEM (Scanning Transmission Electron Microscopy) mode were obtained. ADF images show the heavier parts of the sample as bright (Z-contrast), but some diffraction contrast is also present. For elemental mapping, energy-dispersive spectroscopy was performed using the attached Oxford Instruments EDX detector X-Max ${ }^{\mathrm{N}} 100$ TLE.

\subsection{Atom probe tomography}

The concentration profile along the grain boundaries was measured by atom probe tomography (APT) using the CAMECA LEAP 5000 XR instrument (Fig. S4 in Supplementary Information). The operating conditions were the following: Laser-pulsed mode at a base temperature of $60 \mathrm{~K}$, a laser frequency of $125 \mathrm{kHz}$, and a $60 \mathrm{pJ}$ pulse energy. A 3D atom map (Fig. S4a) is obtained for the creep interrupted Fe-W alloy sample after creep at a temperature of $550{ }^{\circ} \mathrm{C}$ and a stress of $140 \mathrm{MPa}$ for a relative creep lifetime of $t /$ $t_{\mathrm{R}}=0.75$. A sharp reduction in Fe concentration across the grain boundary is observed (Fig. S4b). Simultaneously there is a reduction in the $\mathrm{W}$ concentration in the vicinity of the grain boundary, which ranges from the nominal supersaturated composition of 1 at.\% $\mathrm{W}$ in the matrix to the solubility limit of 0.2 at.\% W within about $30 \mathrm{~nm}$. A weak enhancement in $\mathrm{W}$ concentration is observed at the grain boundary with respect to the depleted zone of the matrix. The matrix composition away from the grain boundary (at about $100 \mathrm{~nm}$ ) is close to the nominal concentration (Fig. S4c). The presence of a $\mathrm{W}$-depleted zone around the grain boundary together with an enrichment of $\mathrm{W}$ at the grain boundary indicates that the 
Fe-W rich phase observed at grain boundaries by SEM-EDX, corresponds to the high-density precipitates measured by synchrotron tomography, which is formed via grain boundary diffusion. An additional grain boundary segregation of carbon was observed, which is a common phenomenon in ferritic steels.

\subsection{Synchrotron X-ray nano-tomography}

Phase contrast tomography with nanometer resolution using coherent X-rays from a synchrotron source was adopted to quantify the 3D structure of the Fe-W alloy samples after the creep tests. Holotomography measurements on the bar-shaped Fe-W samples were performed at the ID16A-NI nano-imaging beamline of the European Synchrotron Radiation Facility (ESRF) in Grenoble, France [27]. This beamline offers an extremely high spatial resolution down to $13 \mathrm{~nm}[27,28]$ by a unique combination of nanofocusing, a very high brilliance and an extreme spatial stability of all components of the setup. A detailed description of this unique instrument can be found elsewhere [28,29].

The maximum photon energy of $33.6 \mathrm{keV}$ available at this beamline was used to optimize the transmission through the sample. The bar-shaped Fe-W sample was mounted on the rotational stage of the tomography setup. Two resolutions of 100 and $30 \mathrm{~nm}$ per voxel were used. The field of view (FOV) at a voxel size of $100 \mathrm{~nm}$ was taken from a sample region with a distance between 0.5 and $3.0 \mathrm{~mm}$ away from the fracture surface for the creep ruptured sample and from the middle of the sample length for the interrupted creep sample. The FOV for measurements at a voxel size of $30 \mathrm{~nm}$ was selected within the FOV probed at a voxel size of $100 \mathrm{~nm}$. As shown in Fig. S1 (Supplementary Information), during the tomography scan the sample was put in the divergent beam downstream of the nano-focus and magnified radiographs were recorded using a charge-coupled device (CCD) with a $2048 \times 2048$ binned pixel array. In total 1800 projections were acquired with an exposure time of $1.00 \mathrm{~s}$ for both resolutions, while the sample was rotated over $180^{\circ}$. Scans at four different focus-to-sample distances were performed for subsequent phase retrieval. A holographic scheme [30] was used to retrieve the phase information by using dedicated programs implemented using the GNU Octave software. Subsequently, the retrieved 2D phase maps were used as input for the tomographic reconstruction of the electron density using the filtered back projection (FBP) algorithm of the ESRF PyHST software package [31]. For each resolution, 3216 slices were reconstructed that correspond to a sample volume of $321.6 \times 321.6 \times 321.6 \mu \mathrm{m}^{3}$ for the $100 \mathrm{~nm}$ voxel size and $96.48 \times 96.48 \times 96.48 \mu \mathrm{m}^{3}$ for the $30 \mathrm{~nm}$ voxel size. The reconstructed 3D volumes were rendered and visualized with the FEI Avizo 8.1 software. The general procedure of data acquisition is illustrated in Fig. S1 (Supplementary Information).

\subsection{Phase segmentation of X-ray tomography data}

The Fe-W alloy samples after the creep tests constitute of three main phases (Fig. S3 in Supplementary Information): (i) the bcc iron-rich matrix with supersaturated tungsten, (ii) empty creep cavities and (iii) W-rich precipitates at creep cavity surfaces and grain boundaries. Apart from a minimum amount of $\mathrm{FeWO}_{4}$ oxides located in the grain interior no other phases were observed. We only focus on the creep cavities and grain-boundary precipitates because they are directly related to the autonomous filling of creep damage by precipitation at the free surface of creep cavities. Since the electron densities of $\mathrm{Fe}_{2} \mathrm{~W}\left(3.352 e / \AA^{3}\right)$, Fe $\left(2.208 e / \AA^{3}\right)$ and vacuum are distinctly different, the contrast between these three phases is significant. Therefore, we can recognize the near-black features as precipitates and bright features as creep cavities in the reconstructed grey-valued slices. Both phases were segmented by applying a threshold value in grey scale of the 3D images. The threshold values were carefully chosen and extensively tested to obtain an optimal contrast between the creep cavities and precipitates. It should be noted that the minimum size of identified object for both resolutions is 8 voxels, that is $8 \times 10^{-3} \mu \mathrm{m}^{3}$ for the $100 \mathrm{~nm}$ resolution and $2.16 \times 10^{-4} \mu \mathrm{m}^{3}$ for the $30 \mathrm{~nm}$ resolution. Objects with a smaller size are regarded as noise and ignored. After the phase segmentation binary images were obtained and exported for further analysis. The electron density of the $\mathrm{FeWO}_{4}\left(1.987 \mathrm{e} / \AA^{3}\right)$ oxide is slightly below the value of Fe $\left(2.208 e / \AA^{3}\right)$ and significantly below that of $\mathrm{Fe}_{2} \mathrm{~W}$ (3.352 e/ $/ \AA^{3}$ ). This strong difference in electron density confirms that the $\mathrm{W}$-rich precipitation probed in the tomography experiments corresponds to $\mathrm{Fe}_{2} \mathrm{~W}$ Laves phase precipitates. The $\mathrm{FeWO}_{4}$ oxides are part of the matrix in the current data treatment.

\subsection{Quantitative analysis of X-ray tomography data}

After identifying the different phases in the Fe-W alloy samples, we quantitatively described their shapes and determined the filling ratio of each individual cavity by examining the co-location of pores and precipitates. The quantitative analysis was employed on the binary images exported from Avizo using a MATLAB program with the DIPimage toolbox [32]. The shape of an object was characterized by shape complexity $\Omega_{3}$ in $3 \mathrm{D}$ and three semi-axes of an equivalent ellipsoid with the same moments of inertia as the real object. Thus the major, intermediate and minor semi-axes (expressed as $a, b$ and $c$, respectively) can be used to calculate the elongation $E$ and the flatness $F$ of the object. By using the three parameters $\Omega_{3}, E$ and $F$, we can unambiguously classify all objects into five different shapes: sphere, equiaxed, rod-like, sheet and complex. A detailed description and criteria for shape classification can be found in our previous work [26].

To quantify the spacing between objects, we calculated the distance for each object to its nearest neighbour based on the coordinates of their centre of mass in 3D. By checking the contact between the cavity and the precipitate, we determined how many precipitates were formed in each cavity and how much of the original cavity volume was occupied by these precipitates. As previously defined [26], we can determine the filling ratio of each cavity by precipitation: $F R=V_{\text {prec }} /\left(V_{\text {cav }}+V_{\text {prec }}\right)$, where $V_{\text {prec }}$ is the volume of the precipitation in contact with the unfilled volume of the cavity $V_{\text {cav }}$. The sum of $V_{\text {cav }}$ and $V_{\text {prec }}$ refers to the cavity volume.

\section{Results}

\subsection{Creep tests and microstructure analysis}

Fig. 1 shows the strain-time curves of the Fe-( $4 \mathrm{wt} \%) \mathrm{W}$ alloy samples until rupture, as well as those for the samples interrupted at a selected fraction of expected rupture time, at a temperature of $550{ }^{\circ} \mathrm{C}$ and a constant stress of 140 or $160 \mathrm{MPa}$. Details regarding the creep conditions and resulting creep time $t$, strain $\varepsilon$ and strain rate $\dot{\varepsilon}$ are given in Table 1 . The creep curves of the interrupted creep tests coincide with the creep curves up to rupture under the same load. The creep curves at 160 MPa show a common creep behaviour, with an initial rapid increase in strain (stage I), then a steady increase in strain (stage II) and finally a strain acceleration until rupture (stage III). The creep curve at $140 \mathrm{MPa}$ shows a stage II creep behaviour with a more gradual crossover in creep rate (see Fig. S2 in Supplementary information for complementary creep curves for a wider range of stresses).

The detailed microstructure analysis (see Fig. 1c and d) indicates that the Fe-W alloy creep samples constitute of three main phases: 

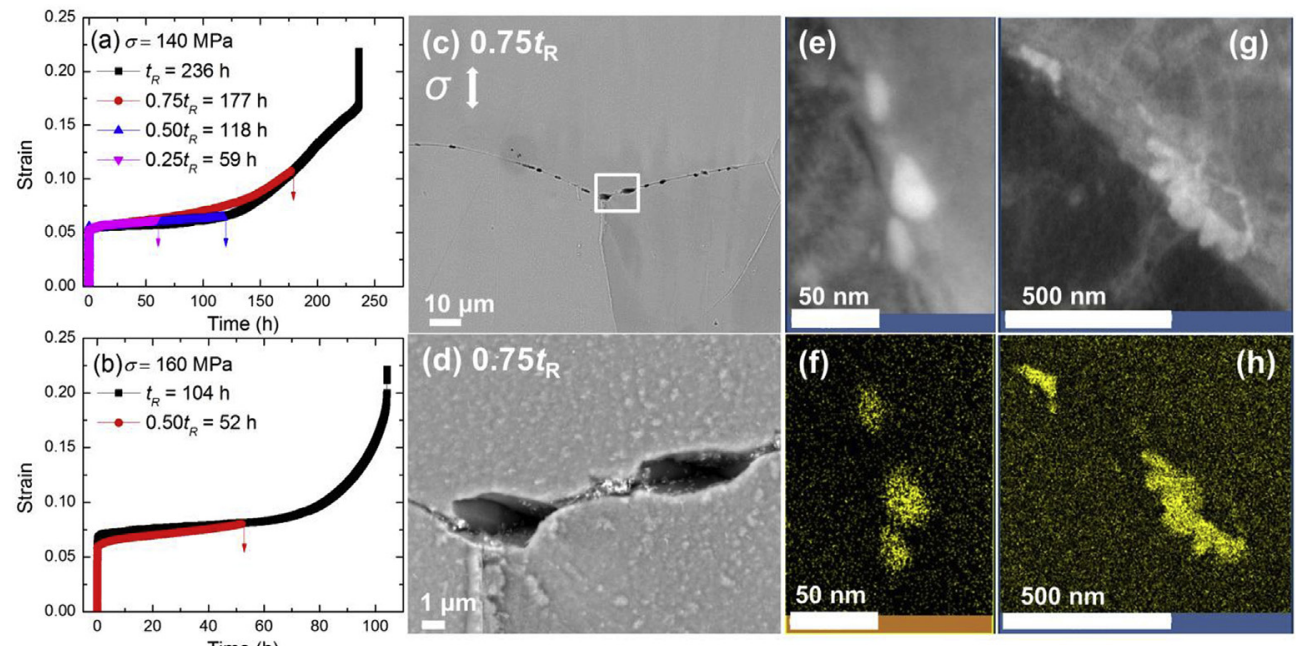

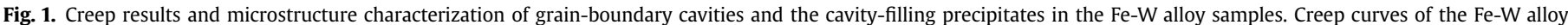

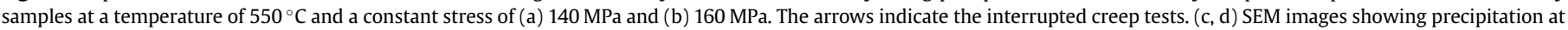

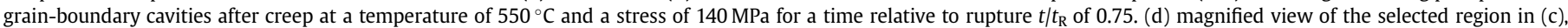

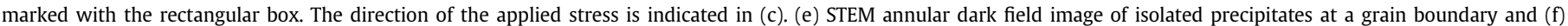
corresponding W elemental mapping. (g) STEM annular dark field image of linked precipitates at a grain boundary and (h) corresponding W elemental mapping.

Table 1

Creep parameters of the Fe-W alloy samples indicating the temperature $T$, the applied stress $\sigma$, the creep time $t$, the relative creep lifetime $t / t_{R}$, the strain $\varepsilon$ and the strain rate $\dot{\varepsilon}$.

\begin{tabular}{lllllll}
\hline Sample & $\begin{array}{l}T \\
{ }^{\circ} \mathrm{C}\end{array}$ & $\begin{array}{l}\sigma \\
\mathrm{MPa}\end{array}$ & $\begin{array}{l}t \\
\mathrm{~h}\end{array}$ & $\begin{array}{l}t / t_{\mathrm{R}} \\
-\end{array}$ & $\begin{array}{l}\varepsilon \\
-\end{array}$ & $\begin{array}{l}\dot{\varepsilon} \\
\mathrm{h}^{-1}\end{array}$ \\
\hline S1 & 550 & 140 & 236 & 1 & 0.218 & $8.7(3) \times 10^{-5}$ \\
S2 & 550 & 140 & 177 & 0.75 & 0.107 & $1.7(6) \times 10^{-4}$ \\
S3 & 550 & 140 & 118 & 0.50 & 0.065 & $7.6(2) \times 10^{-5}$ \\
S4 & 550 & 140 & 59 & 0.25 & 0.062 & $1.3(2) \times 10^{-4}$ \\
\hline S5 & 550 & 160 & 104 & 1 & 0.222 & $2.0(5) \times 10^{-4}$ \\
S6 & 550 & 160 & 52 & 0.50 & 0.081 & $3.1(8) \times 10^{-5}$ \\
\hline
\end{tabular}

(i) the iron-rich matrix with supersaturated tungsten, (ii) empty creep cavities at grain boundaries and (iii) precipitates at the creep cavity surfaces. These precipitates are also found at the fracture surface of the creep-failed samples (see Fig. S3 in Supplementary Information). As shown in Fig. 1e-h, transmission electron microscopy indicates that the precipitates located at the grain boundaries are $W$ rich. HREM measurements on grain-boundary precipitates show that the precipitates correspond to the $\mathrm{Fe}_{2} \mathrm{~W}$ Laves phase. Additional EBSD and X-ray diffraction measurements confirmed the structure of the $\mathrm{Fe}_{2} \mathrm{~W}$ Laves phase. Complementary atom probe tomography across the grain boundary reveals a reduction in the $\mathrm{W}$ concentration in the vicinity of the grain boundary, which ranges from the nominal supersaturated composition of 1 at.\% $\mathrm{W}$ in the matrix to the solubility limit of 0.2 at.\% $\mathrm{W}$ within about $30 \mathrm{~nm}$ of the grain boundary (see Fig. S4 in Supplementary Information).

\subsection{X-ray tomography}

Tomographic 3D images of the creep-interrupted Fe-W alloy samples were collected and reconstructed for two resolutions: medium resolution (with voxel size of $100 \mathrm{~nm}$ ) and high resolution (with a voxel size of $30 \mathrm{~nm}$ ). In Fig. 2 the creep samples at a stress of $140 \mathrm{MPa}$ for different times relative to the rupture lifetime $t_{\mathrm{R}}$ are shown in medium resolution (see Fig. S5 in Supplementary Information for the corresponding data for a stress of $160 \mathrm{MPa}$ ). Cavities and precipitates are segmented and labelled in red and green, respectively. The images clearly show that the number of cavities increases with the creep time. In the early interrupted creep samples $\left(0.25 t_{R}\right.$ and $\left.0.50 t_{R}\right)$, most of the cavities and precipitates are very small with an average equivalent diameter of about $0.55 \mu \mathrm{m}$. In the creep sample interrupted at $0.75 t_{\mathrm{R}}$ and the ruptured sample, the simultaneous growth of cavities and precipitates results in a larger variety of shapes, ranging from small isolated spherical (or equiaxed) shapes to more extended complex shapes. From Fig. 2c and $d$ it can be seen clearly that the grain boundaries are delineated by the spatial distribution of cavities and precipitates and that the creep damage is preferentially formed there. Given the large field of view we have a good overview of the spatial distribution of cavities and precipitates within the microstructure. Fig. 2a and b indicate that a lot of cavities are spatially connected to one or more precipitates. In Fig. 2c and d the largest cavities (at grain boundaries perpendicular or inclined to the loading axis) are linked to and often partly filled with precipitates. Fig. $2 \mathrm{~d}$ also shows that complex cavities located at inclined and transverse grain boundaries tend to join at grain corners and show a partial filling by precipitates. All these features provide indirect evidence that the precipitation takes place inside the creep cavities.

More detailed views to clarify how the cavities are filled by precipitates are obtained by additional tomographic measurements on the same sample volume with a higher resolution (using a voxel size of $30 \mathrm{~nm}$ ). In Figs. S6 and S7 (Supplementary Information) high-resolution subsets of the lower resolution data are shown for the sample loaded at a stress of 140 and $160 \mathrm{MPa}$, respectively. With the higher resolution, finer details can be resolved that are not revealed in the lower resolution datasets. The enhanced resolution also affects the apparent shape classification of the object. A direct comparison of the same field of view (FOV) in medium and in high resolution is presented in Figs. S8-S9 (Supplementary Information) for different samples, while the overall microstructure is represented in Movies S1-S2 (Supplementary Information).

Supplementary video related to this article can be found at doi:10.1016/j.actamat.2019.01.014.

While the fine features are best captured in the high-resolution images, the medium-resolution images cover a larger sample volume and thereby provide a better overview with a statistically 


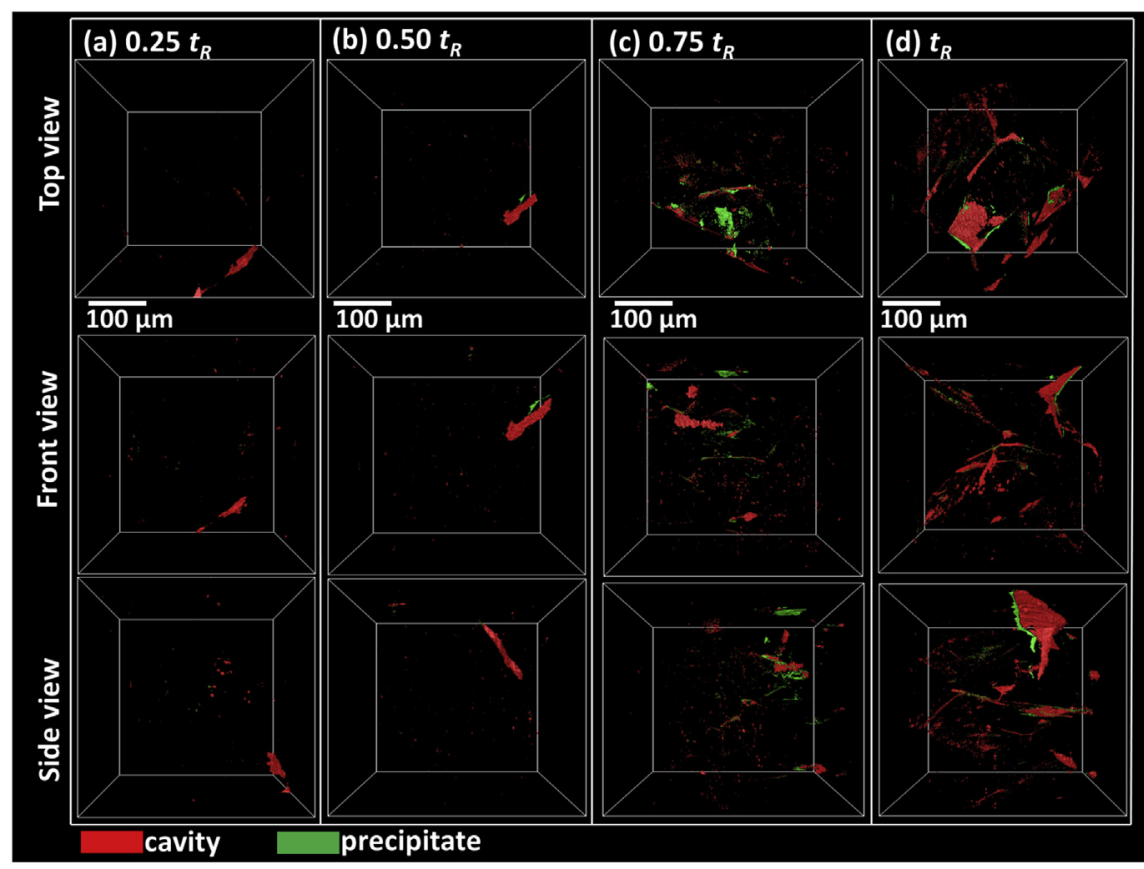

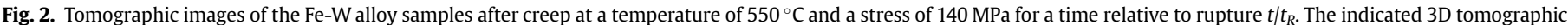

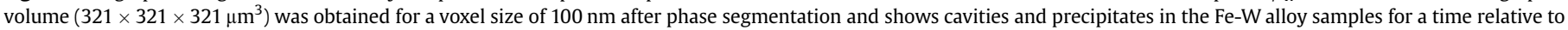
rupture $t / t_{R}$ of (a) 0.25 , (b) 0.50 , (c) 0.75 and (d) 1.00 , where $t_{R}$ is the rupture time. The applied stress is normal to the top view.

more relevant determination of size distributions for the cavities and the precipitates. Therefore, the statistical information is derived from images with a medium resolution. Figs. S10 and S11 (Supplementary Information) show the number and volume distributions of cavities and precipitates for the studied samples. All number distributions are found to correspond to a lognormal distribution (fit parameters are listed in Table S1 in Supplementary Information). It is found that at stresses of 140 and $160 \mathrm{MPa}$ both the number density $N_{0}$ and the average diameter $\bar{d}$ of the cavities increase with the creep time. In all cases the average diameter of the precipitates is slightly smaller than that of cavities, indicating that the precipitates are lagging behind in their development compared to the cavities, as expected for the damage-induced precipitation in self-healing alloys.

\subsection{Identification of isolated and linked cavities}

Previous studies have shown that the growth behaviour of isolated and linked cavities is very different [26,33]. An effective method to identify these two types of cavities is by analysing their shape and their size relative to the cavity spacing. Using the previously defined shape classification scheme [26], the following cavity shapes are defined: spherical, equiaxed, rod-like, sheet and complex. In Fig. 3 experimental examples of these shapes observed at the initial creep stage (at $0.25 t_{\mathrm{R}}$ ) and at rupture $\left(t_{\mathrm{R}}\right)$ are presented. Spherical and equiaxed cavities tend to form in isolated positions. The rod-like, sheet and complex cavities are presumed to be coalesced cavities, as necking is frequently observed in the 3D shapes. In addition to the shape classification, a second criterion

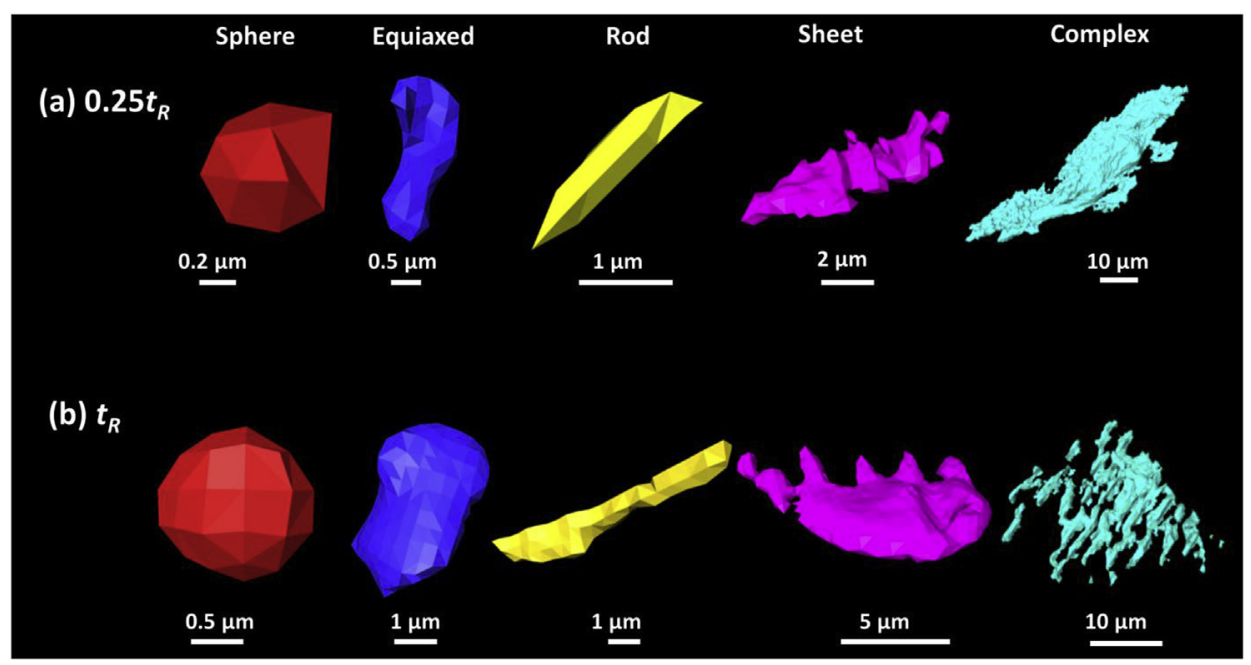

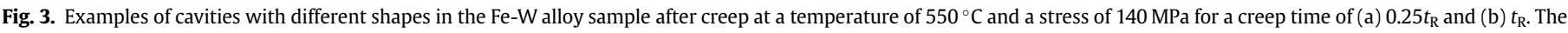
cavities are classified into five different shapes: sphere, equiaxed, rod, sheet and complex. 
(a) Top view

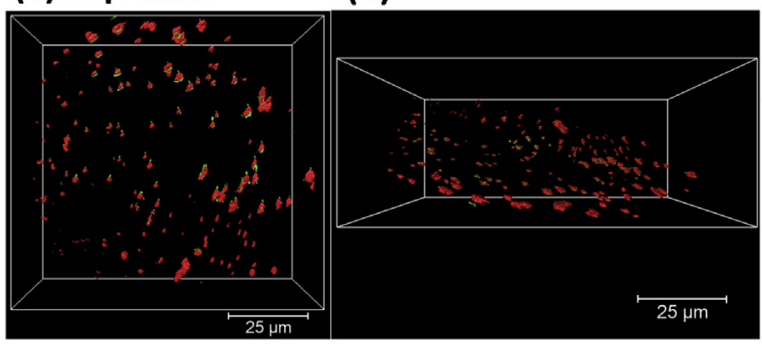

(c)

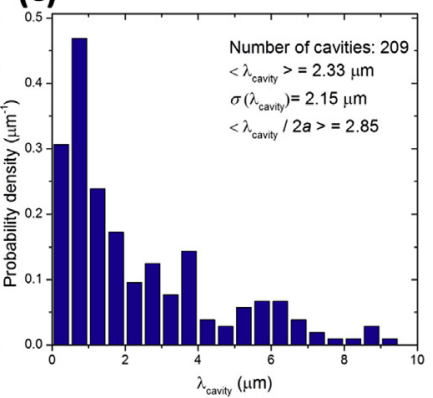

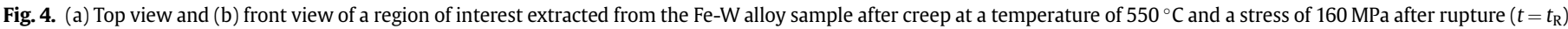

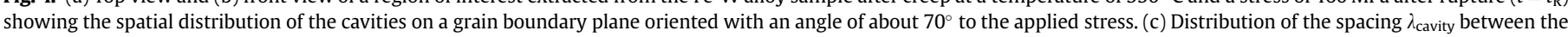

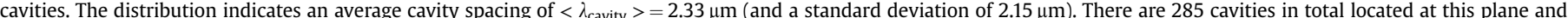

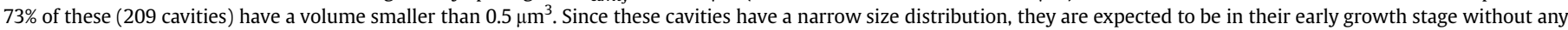

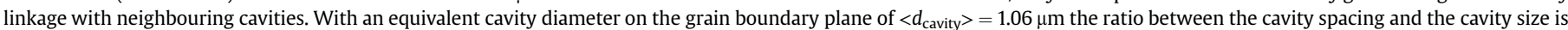
$\left\langle\lambda_{\text {cavity }}\right\rangle \mid\left\langle d_{\text {cavity }}\right\rangle=2.85$. The equivalent diameter of each cavity in the grain boundary plane is calculated as $d_{\text {cavity }}=2(a b)^{1 / 2}$.

separates isolated and linked cavities by comparing the size of the cavity to the cavity spacing. If the major axes of a cavity with a rodlike, sheet or complex shape is larger than the average cavity spacing $\left\langle\lambda_{\text {cavity }}>\right.$, this cavity is considered to be a linked cavity (composed of several nucleated cavities). All other cavities (mainly the cavities with a spherical or equiaxed shape) are regarded as isolated. An average cavity spacing of $\left\langle\lambda_{\text {cavity }}\right\rangle=2.33 \mu \mathrm{m}$ is estimated from an quantitative analysis of the precipitation on the grain boundary plane presented in Fig. 4. By quantifying the cavity shapes and comparing their major axes to $\left\langle\lambda_{\text {cavity }}>\right.$ the isolated and linked cavities can now be separated explicitly.

Fig. 5 shows the number density and volume fraction of cavities classified into $(i)$ shape categories and (ii) isolated and linked cavities. The number density of creep cavities is dominated by the spherical cavities, while complex cavities are relatively rare in number. In contrast, the volume fraction of cavities is dominated by complex cavities, whereas spherical cavities contribute very little to the volume fraction (as the complex cavities are generally much larger than spherical cavities).
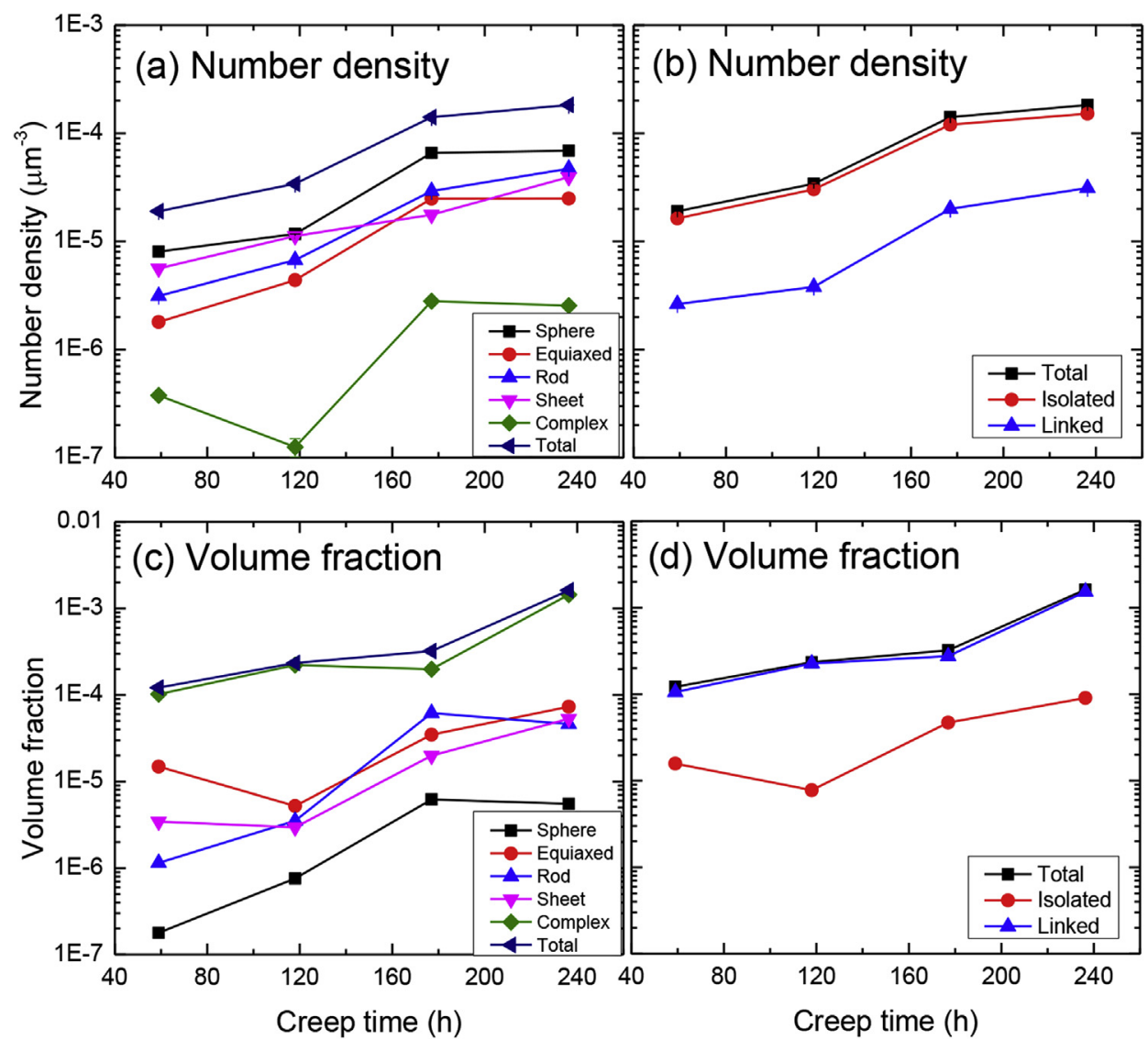

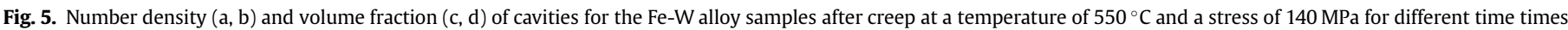
with $(a, c)$ cavities classified by shape and (b, d) cavities classified as isolated or linked. 
$\sigma=140 \mathrm{MPa}$

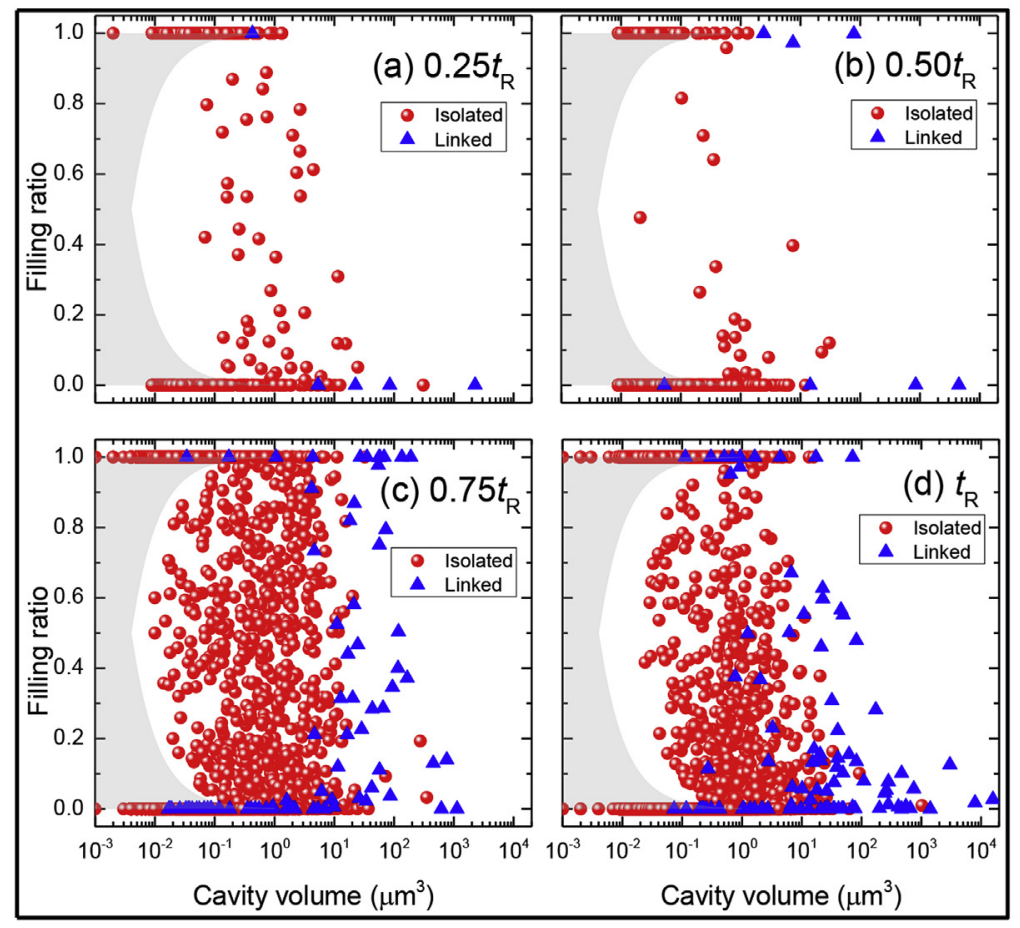

$\sigma=160 \mathrm{MPa}$

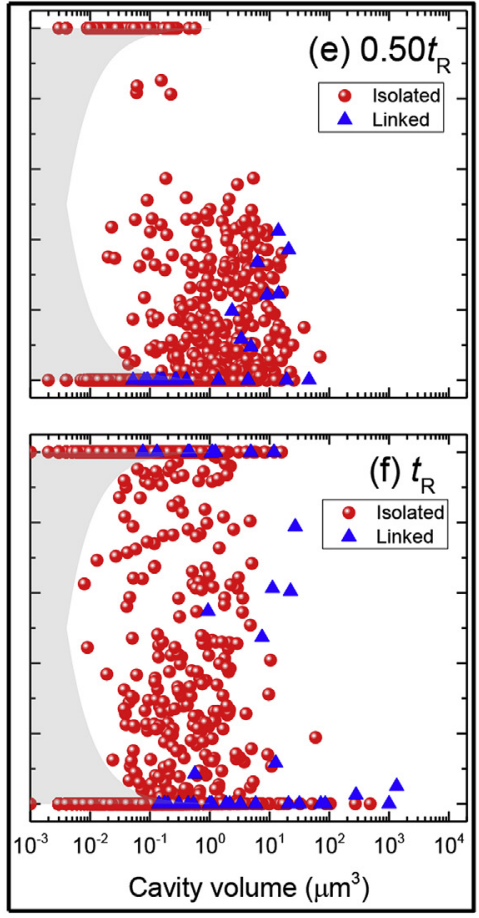

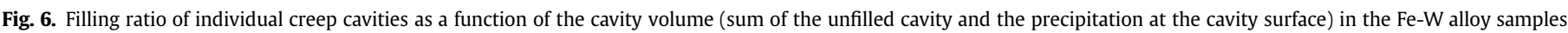

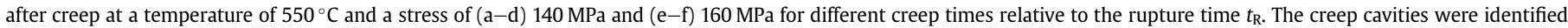

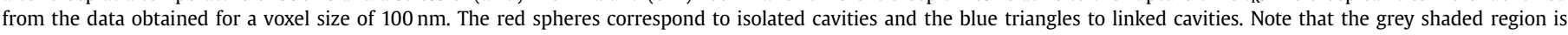

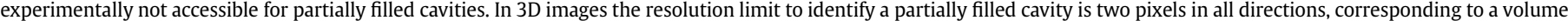

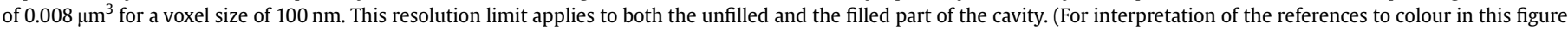
legend, the reader is referred to the Web version of this article.)

\subsection{Filling of individual cavities}

The filling ratio FR of a creep cavity is defined as the precipitation volume at the cavity surface divided by the combined volume of the connected cavitation and precipitation ( $F R=0$ for an unfilled cavity and $F R=1$ for a fully filled cavity). In Fig. $6 a-d$ the measured $F R$ value for each (unfilled, partially-filled or fully-filled) cavity is plotted for each creep cavity as a function of its volume at different relative creep times for the four samples loaded at $140 \mathrm{MPa}$ and in Fig. 6 e and for the two samples loaded at $160 \mathrm{MPa}$. Fig. 6 clearly shows that the number of cavities, the volume distribution and the distribution of filling ratios evolve with the creep lifetime. The volume of the unfilled cavities spans a wider range than the volume of the fully filled cavities and the volume of the largest unfilled cavities is several orders of magnitude bigger than that of the largest fully filled cavities. This indicates once again that the precipitates form later than the cavities, which is fully in line with the proposed self-healing mechanism. Although there is a lower amount of partially filled cavities present in the samples with shorter creep times $\left(0.25 t_{R}\right.$ and $\left.0.50 t_{R}\right)$, the observed filling ratios span over the whole range from 0 to 1 , indicating that at a stress of $140 \mathrm{MPa}$ the lowest creep lifetime of $0.25 t_{\mathrm{R}}=59 \mathrm{~h}$ is already sufficient to fill the earliest nucleated creep cavities at this stress level. As is to be expected, the linked cavities are predominantly observed in the later creep stages and are generally the largest in size.

For the samples loaded at a higher stress of $160 \mathrm{MPa}$ (Fig. 6e and f), where the growth rate of the cavities should be higher than at $140 \mathrm{MPa}$, the maximum cavity volume is again much larger for the unfilled cavities than for the fully filled cavities. For a creep lifetime of $0.50 t_{\mathrm{R}}=52 \mathrm{~h}$ the filling ratio of most of the partially filled cavities now only ranges up to 0.6 (see Fig. 6e), indicating that complete filling has not been achieved within this creep time. In contrast, for the ruptured sample with a creep time of $t_{\mathrm{R}}=104 \mathrm{~h}$ the filling ratio of the partially filled cavities again occupy the whole range from 0 to 1 (see Fig. 6f). This means that for a stress of $160 \mathrm{MPa}$ the filling time for an isolated cavity is between 52 and $104 \mathrm{~h}$.

Examples of the topology of partially filled cavities resolved from the high-resolution data of the Fe-W alloy samples a stress of $140 \mathrm{MPa}$ for creep times of $0.25 t_{\mathrm{R}}$ and $0.50 t_{\mathrm{R}}$ are shown in Figs. 7 and 8 , respectively. In Fig. 7 the four partially filled cavities for the shortest creep time of $t=0.25 t_{\mathrm{R}}$ all show rich details in shape with local precipitation on only one location of the cavity surface. The data suggest that the precipitate first forms at a specific location at the cavity surface and from thereon grows covering an increasing area on the creep cavity surface. The precipitation will block the growths of the cavity in this direction, while the cavity may continue to grow in other directions. For the longer creep time of $t=0.50 t_{\mathrm{R}}$, shown in Fig. 8, the partially filled cavities in most cases show that multiple precipitates have formed on the creep cavity surface. Additional examples for a creep lifetime of $0.75 t_{R}$ and at rupture $\left(t_{R}\right)$ at a stress of $140 \mathrm{MPa}$ are presented in Figs. S12 and S13 (Supplementary Information), respectively.

Examples of partially filled cavities for the higher stress of $160 \mathrm{MPa}$ at a creep lifetime of $0.50 t_{\mathrm{R}}$ are shown in Fig. 9. Again, the cavity surface is decorated with several precipitates at different locations on the creep cavity surface. Similar features are observed for the sample loaded to failure $\left(t=t_{\mathrm{R}}\right)$ at a stress of $160 \mathrm{MPa}$, as shown in Fig. S14 (Supplementary Information). 


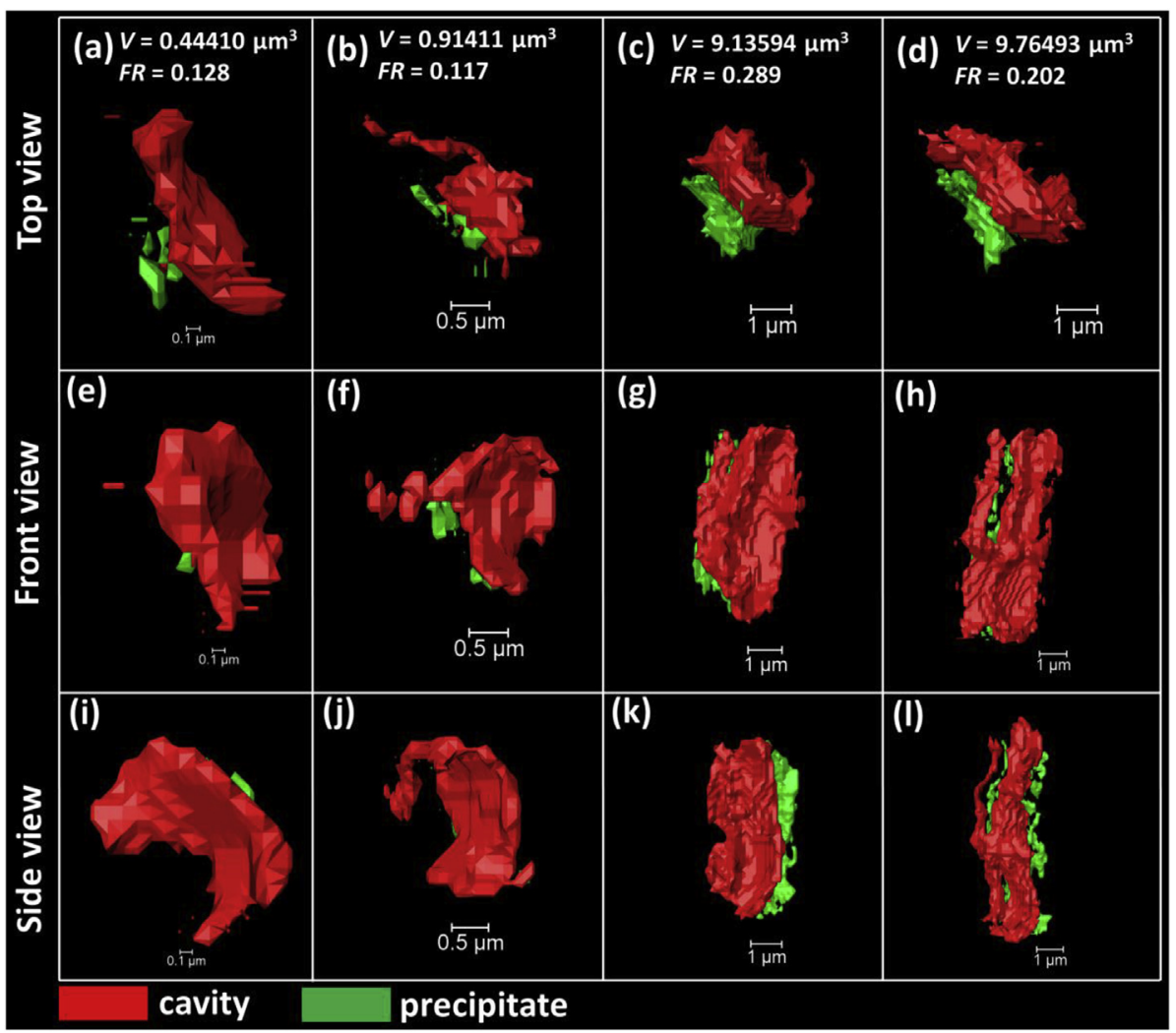

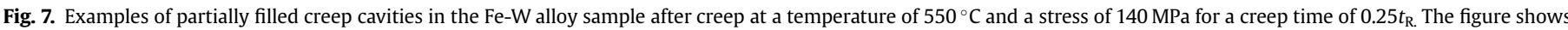

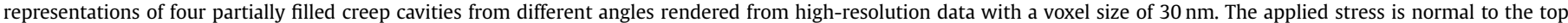
view.

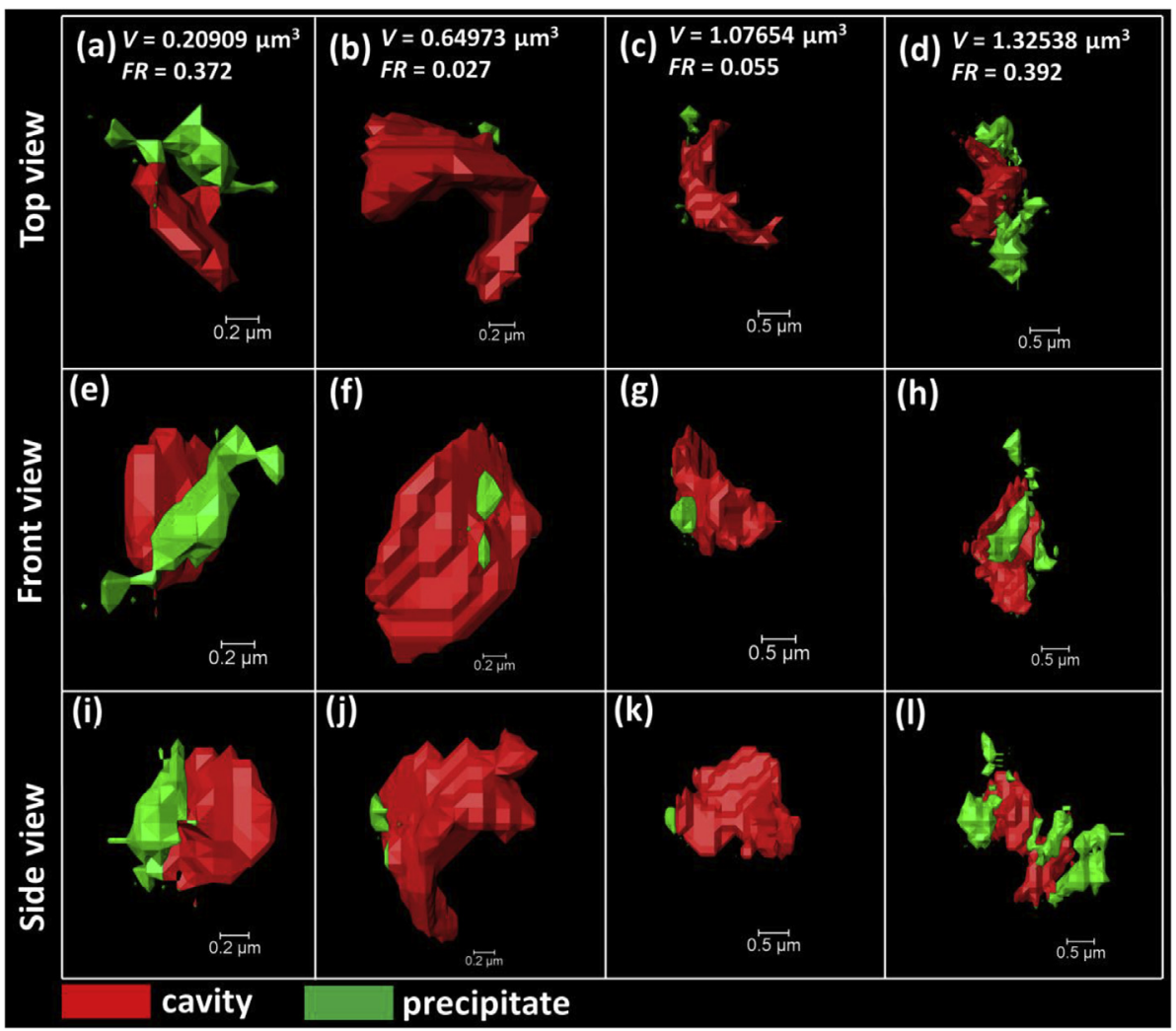

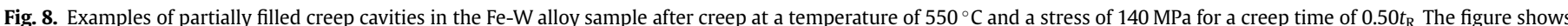

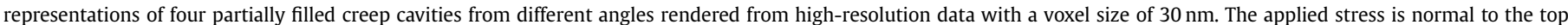
view. 


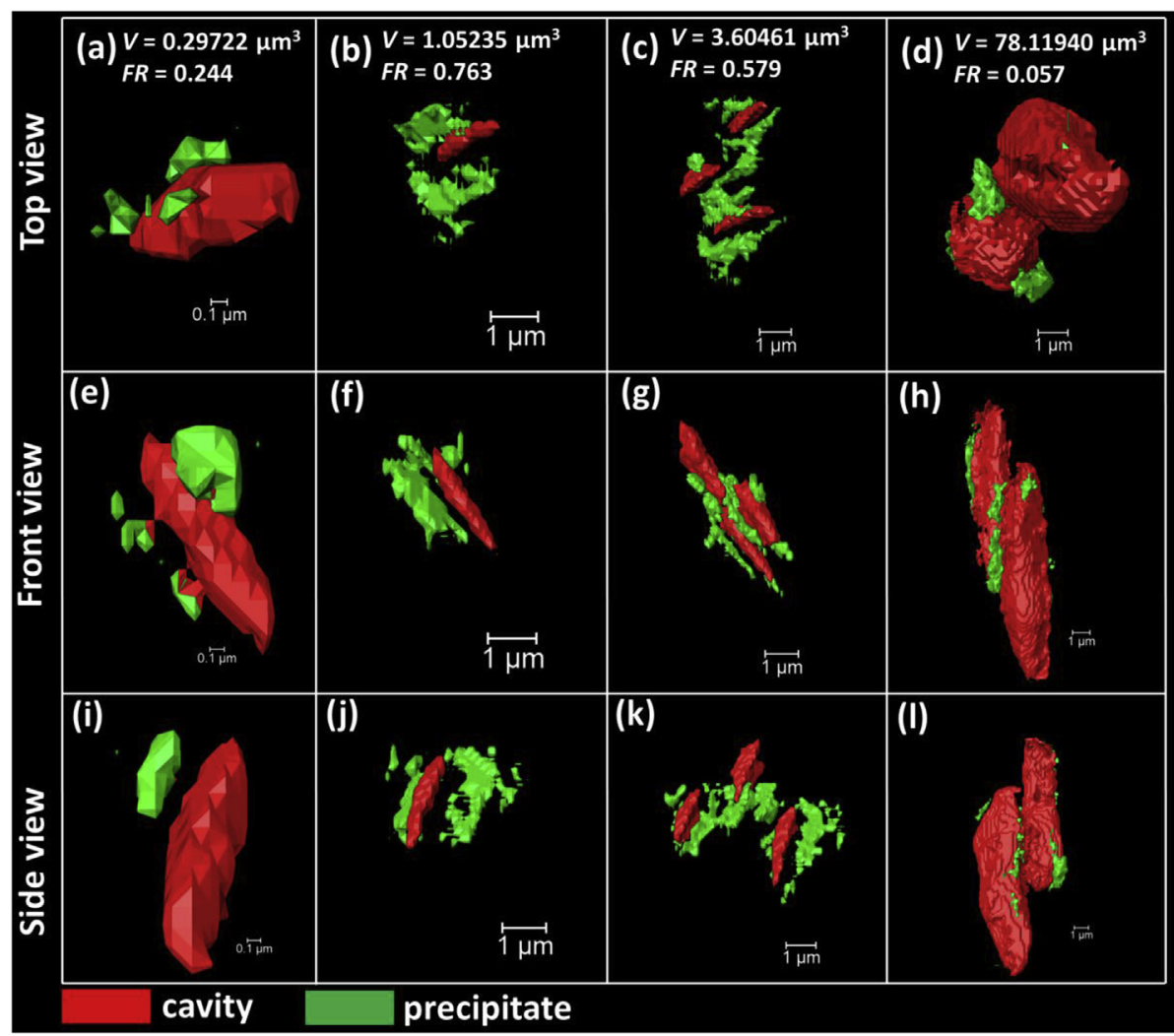

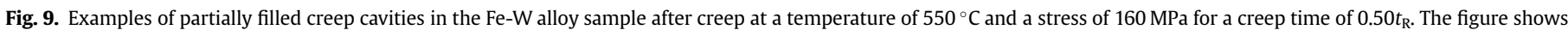

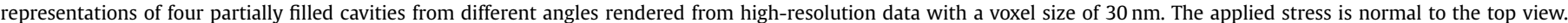

\section{Discussion}

\subsection{Autonomous filling of creep cavities by precipitation}

Extensive evidence obtained from the tomographic characterization demonstrates that the precipitates form at the free cavity surface and that this precipitation is filling the cavity during the entire creep process. As shown in Fig. 2 the cavities predominantly form at transverse, inclined grain boundaries and grain corners. The precipitates always adapt their morphologies to match the remaining open cavity. Detailed views of the microstructures in Figs. 7-9 clearly show that multiple precipitates can form at different sites in the same cavity. When the precipitates on the creep surface grow in size and density they can connect and even form more extended line structures. In the early growth stage the morphology of the precipitates formed at small cavities is irregular and reflects the morphology of the specific cavity. The maps of the filling ratio versus cavity size for different creep times show that the unfilled cavities have a size range that extends up to much larger volumes than those of the partially-filled and fully-filled cavities.

According to our previous studies [16,26], cavity filling is initiated once a certain volume $V_{0, \text { cav }}$ is reached. The value of $V_{0 \text {,cav }}$ depends on the local grain-boundary conditions, in particular the orientation to the applied stress. For the filling of specific isolated cavities the filling ratio increases continuously to reach full filling $(F R=1)$ when the precipitate growth rate exceeds the cavity growth rate, as a result of the flux of supersaturated $\mathrm{W}$ atoms that diffuse towards the cavity surface and combine with the Fe atoms to form $\mathrm{Fe}_{2} \mathrm{~W}$ precipitates at the cavity surface. However, the growth of the cavities is accelerated by linkage with neighbouring cavities. In this case, the filling ratio drops continuously, as the filling cannot keep up with the cavity growth once linkage sets in. The experimental data on the filling ratio versus cavity size of the large number of observed cavities illustrates these differences in behaviour.

\subsection{Nucleation and growth of creep cavities and precipitates}

The healing kinetics of the cavities is controlled by the balance between the cavity growth rate and the precipitation rate at the cavity surface. To analyse the filling kinetics it is essential to study the nucleation and growth of both the cavities and the precipitates. Since the resolution limit of the tomographic images ( $\approx 2$ times of the voxel size, i.e. $60 \mathrm{~nm}$ ) is close to the predicted size of the critical nucleus of about $50 \mathrm{~nm}$ for a creep cavity [34], all formed cavities should be observable in the $3 \mathrm{D}$ images. However, as a result of linkage the number of observed cavities is generally lower than the original number of nucleated cavities. For cavities with a long axis $2 a$ and an average cavity spacing $<\lambda_{\text {cavity }}>$ the linked cavities contain an estimated number of $2 a \mid<\lambda_{\text {cavity }}>$ originally nucleated cavities (linear chain). This estimate can be used to evaluate the effect of linkage on the cavity number.

As shown in Fig. 10, the observed cavity number forms a lower bound and the corrected cavity number forms an upper bound of the formed nuclei. The slope of the linear fits in Fig. 10a for the average cavity number per grain as a function of the creep time indicates that at a temperature of $550^{\circ} \mathrm{C}$ and a stress of $140 \mathrm{MPa}$ cavity nucleation takes place continuously at a rate of about one cavity per grain per hour. This steady-state nucleation rate is consistent with the expectations for stage II creep.

The number of precipitates formed at each cavity was also determined from the 3D tomography images. In Fig. 10c the average 

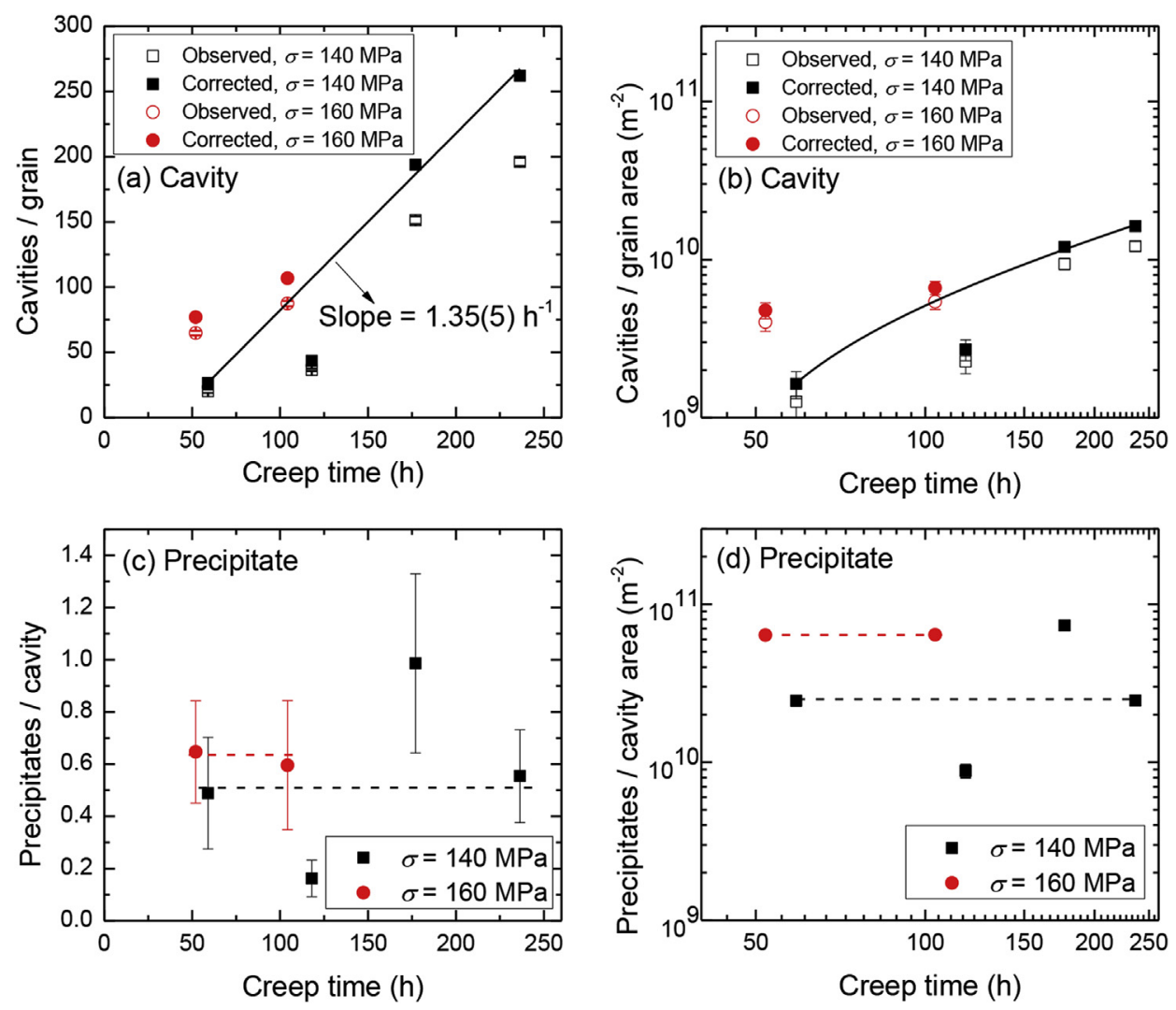

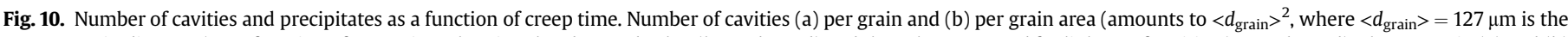

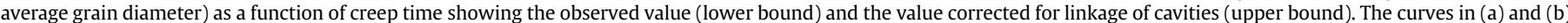

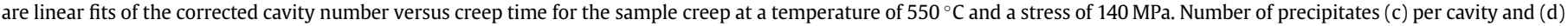
per cavity area showing a constant behaviour over creep time. The curves in (c) and (d) are a guide to the eye.

number of precipitates in each cavity is plotted as a function of the creep time and the number of precipitates per cavity surface area versus creep time is shown in Fig. 10d. The data clearly show that the number of precipitates per cavity and the number of precipitates per cavity area are more or less constant over the entire creep process. This suggests that the number of precipitates correlates with the dislocation density, which is expected to be relatively constant since there is a balance between the formation and the annihilation of dislocations during the secondary creep stage. Figs. 10c and 10d also show that the number of precipitates formed at a stress of $160 \mathrm{MPa}$ is slightly higher than that at a stress of $140 \mathrm{MPa}$, implying that a higher dislocation density enhances the precipitation in agreement with the observation that nucleation of precipitates is enhanced by plastic deformation during ageing [13].

In-situ studies on cavity growth during creep in brass $[35,36]$ and copper [37] show a large variety in growth behaviour for single cavities. An average volumetric growth rate $\mathrm{d} V / \mathrm{d} t$ is thus required to describe the overall growth behaviour. To analyse the growth rates of both the cavities and precipitates, their average volumes divided into isolated and linked cavities and precipitates are shown as a function of the creep time in Fig. S15 (Supplementary Information). The average volume as a function of the creep time $t$ follows a power law, expressed as $\langle V\rangle=k t^{n}$, for both cavities and precipitates (fit parameters of $k$ and $n$ are listed in Table S2 in Supplementary Information). For isolated cavities and precipitates, the growth exponents are identical and equal to $n=0.8$. For linked cavities the power law exponent increases to $n=1.3$. Linked precipitates are expected to form within the same cavity and show the same growth exponent as unlinked cavities $(n=0.8)$. For comparison, the fitting parameters of the growth parameters for the Fe-Au alloy [26] are also listed. The significant difference in growth rate is attributed to a much slower volume diffusivity of $\mathrm{W}$ compared to $\mathrm{Au}$ in $b c c$ iron as $D_{\mathrm{Au}} / D_{\mathrm{W}} \approx 10^{3}$ at $550^{\circ} \mathrm{C}$ [25].

The time exponent $n=0.8$ for the precipitate growth in a grainboundary cavity is consistent with previously reported computational studies. Aaron and Aaronson [38] found that the time exponent for the volumetric growth of precipitates at grain boundaries is between 0.66 and 1 with an average of 0.81 . A recent study by Versteylen and coworkers [39] showed that the time exponent for the filling of a grain-boundary cavity by diffusional precipitation ranges from 0.5 to 1 . The actual value depends on $(i)$ the ratio between the cavity spacing and the cavity radius and (ii) the ratio between the grain-boundary diffusivity and bulk diffusivity of the supersaturated solute atoms. For isolated cavities a diffusion process with a growth exponent of about 0.8 is expected. As found experimentally (see Fig. S15 in Supplementary Information), the linkage of cavities significantly accelerates the cavity growth, resulting in an increase of the growth exponent to 1.3. The solute transport towards the precipitate occurs via fast transport along the grain boundaries and is rate limited by the diffusion from the bulk towards the grain boundary [40]. The characteristic maximum diffusion length for $\mathrm{W}$ diffusion from the bulk to the grain boundary is $2 \sqrt{D_{W} t_{R}} \approx 100 \mathrm{~nm}$ for the rupture time at a stress of $140 \mathrm{MPa}$, which is consistent with the APT data (see Fig. S4 in Supplementary Information). 


\section{Conclusions}

The self-healing process of creep damage is studied in detail in a high-purity binary $\mathrm{Fe}-\mathrm{W}$ alloy at a temperature of $550{ }^{\circ} \mathrm{C}$ and at several applied stresses. The spatial distribution and morphology of both the precipitates and cavities are monitored by synchrotron $\mathrm{X}$ ray nano-tomography. The experimental data demonstrate the autonomous filling of nucleated creep cavities by the formation of $\mathrm{W}$-rich Laves phase precipitates. The 3D images obtained at a medium resolution ( $100 \mathrm{~nm}$ voxel size) provide detailed statistics on the creep cavities, while the 3D images obtained at a high resolution ( $30 \mathrm{~nm}$ voxel size) provide a detailed view on the morphology of the partially filled cavities. Two different trends are observed for the cavity filling of isolated and linked cavities, respectively. For isolated cavities a complete filling is often obtained, while for linked generally only a partial filling is found. This indicates for isolated cavities that the precipitation rate exceeds the cavity growth rate, while the precipitation cannot catch up with the cavity growth when coalescence sets in. The demonstrated self-healing potential of supersaturated $\mathrm{W}$ atoms in iron-based alloys provides new perspectives on the role of $\mathrm{W}$ for high-temperature creepresistant steels. The presented self-healing mechanism operates in parallel to the solid-solution strengthening without weakening it. This study shows a promising future for the control of creep damage by the addition of affordable alloying elements that enable the self-healing of creep damage.

\section{Acknowledgements}

This research is financially supported by the innovationoriented research program (IOP) on self-healing materials of the Dutch Ministry of Economic Affairs, Agriculture and Innovation (Project SHM012011) and a grant from the China Scholarship Council. We thank Joost van Meel and Dominique Ngan-Tillard at the Faculty of Civil Engineering and Geosciences, Delft University of Technology for providing the access to FEI Avizo. We acknowledge the European Synchrotron Radiation Facility for provision of synchrotron radiation facilities (proposal MA3497) and thank the beamline staff for assistance in using beamline ID16A-NI.

\section{Appendix A. Supplementary data}

Supplementary data to this article can be found online at https://doi.org/10.1016/j.actamat.2019.01.014.

\section{References}

[1] M. Taneike, F. Abe, K. Sawada, Creep-strengthening of steel at high temperatures using nano-sized carbonitride dispersions, Nature 424 (2003) 294-296.

[2] H.K.D.H. Bhadeshia, Design of ferritic creep-resistant steels, ISIJ Int. 41 (2001) 626-640.

[3] K. Maruyama, K. Sawada, J. Koike, Strengthening mechanisms of creep resistant tempered martensitic steel, ISIJ Int. 41 (2001) 641-653.

[4] Q. Lu, W. Xu, S. van der Zwaag, The design of a compositionally robust martensitic creep-resistant steel with an optimized combination of precipitation hardening and solid-solution strengthening for high-temperature use, Acta Mater. 77 (2014) 310-323.

[5] L. Sun, T.H. Simm, T.L. Martin, S. McAdam, D.R. Galvin, K.M. Perkins P.A.J. Bagot, M.P. Moody, S.W. Ooi, P. Hill, M.J. Rawson, H.K.D.H. Bhadeshia, A novel ultra-high strength maraging steel with balanced ductility and creep resistance achieved by nanoscale $\beta$-NiAl and Laves phase precipitates, Acta Mater. 149 (2018) 285-301.

[6] M.D. Hager, P. Greil, C. Leyens, S. van der Zwaag, U.S. Schubert, Self-healing materials, Adv. Mater. 22 (2010) 5424-5430.

[7] S. van der Zwaag, E. Brinkman (Eds.), Self Healing Materials: Pioneering Research in the Netherlands, IOS Press, Amsterdam, 2015.

[8] N.H. van Dijk, S. van der Zwaag, Self healing phenomena in metals, Adv. Mater Interfaces 5 (2018) 1800226.

[9] K. Laha, J. Kyono, S. Kishimoto, N. Shinya, Beneficial effect of B segregation on creep cavitation in a type 347 austenitic stainless steel, Scripta Mater. 52
(2005) 675-678.

[10] K. Laha, J. Kyono, N. Shinya, An advanced creep cavitation resistance Cucontaining $18 \mathrm{Cr}-12 \mathrm{Ni}-\mathrm{Nb}$ austenitic stainless steel, Scripta Mater. 56 (2007) 915-918.

[11] K. Laha, J. Kyono, T. Sasaki, N. Shinya, Improved creep strength and creep ductility of type 347 austenitic stainless steel through the self-healing effect of boron for creep cavitation, Metall. Mater. Trans. 36 (2005) 399-409.

[12] N. Shinya, Self healing of mechanical damage in metallic materials, Adv. Sci. Technol. 54 (2008) 152-157.

[13] S. Zhang, J. Kohlbrecher, F.D. Tichelaar, G. Langelaan, E. Brück, S. van der Zwaag, N.H. van Dijk, Defect-induced Au precipitation in Fe-Au and $\mathrm{Fe}-\mathrm{Au}-\mathrm{B}-\mathrm{N}$ alloys studied by in situ small-angle neutron scattering, Acta Mater. 61 (2013) 7009-7019.

[14] S. Zhang, C. Kwakernaak, W.G. Sloof, E. Brück, S. van der Zwaag, N.H. van Dijk, Self-healing of creep damage by gold precipitation in iron alloys, Adv. Eng. Mater. 17 (2015) 598-603.

[15] S. Zhang, C. Kwakernaak, F.D. Tichelaar, W.G. Sloof, M. Kuzmina, M. Herbig, D. Raabe, E. Brück, S. van der Zwaag, N.H. van Dijk, Autonomous repair mechanism of creep damage in Fe-Au and Fe-Au-B-N alloys, Metall. Mater. Trans. 46 (2015) 5656-5670.

[16] S. Zhang, H. Fang, M.E. Gramsma, C. Kwakernaak, W.G. Sloof, F.D. Tichelaar, M. Kuzmina, M. Herbig, D. Raabe, E. Brück, S. van der Zwaag, N.H. van Dijk, Autonomous filling of grain-boundary cavities during creep loading in Fe-Mo alloys, Metall. Mater. Trans. 47 (2016) 4831-4844.

[17] R.L. Klueh, Elevated temperature ferritic and martensitic steels and their application to future nuclear reactors, Int. Mater. Rev. 50 (2005) 287-310.

[18] A. Puype, L. Malerba, N. De Wispelaere, R. Petrov, J. Sietsma, Effect of W and N on mechanical properties of reduced activation ferritic/martensitic EUROFERbased steel grades, J. Nucl. Mater. 502 (2018) 282-288.

[19] T. Sakthivel, S.P. Selvi, K. Laha, An assessment of creep deformation and rupture behaviour of $9 \mathrm{Cr}-1.8 \mathrm{~W}-0.5 \mathrm{Mo}-\mathrm{VNb}$ (ASME grade 92) steel, Mater. Sci. Eng., A 640 (2015) 61-71.

[20] C.S. Smith, Precipitation hardening in the Fe-W system, J. Appl. Phys. 12 (1941) 817-822.

[21] P.J. Ennis, A. Zielinska-Lipiec, O. Wachter, A. Czyrska-Filemonowicz, Microstructural stability and creep rupture strength of the martensitic steel P92 for advanced power plant, Acta Mater. 45 (1997) 4901-4907.

[22] K. Sawada, M. Takeda, K. Maruyama, R. Ishii, M. Yamada, Y. Nagae, R. Komine, Effect of $W$ on recovery of lath structure during creep of high chromium martensitic steels, Mater. Sci. Eng., A 267 (1999) 19-25.

[23] D. Rojas, J. Garcia, O. Prat, G. Sauthoff, A.R. Kaysser-Pyzalla, 9\% Cr heat resistant steels: alloy design, microstructure evolution and creep response at 650 ${ }^{\circ} \mathrm{C}$, Mater. Sci. Eng., A 528 (2011) 5164-5176.

[24] A. Aghajani, C. Somsen, G. Eggeler, On the effect of long-term creep on the microstructure of a $12 \%$ chromium tempered martensite ferritic steel, Acta Mater. 57 (2009) 5093-5106.

[25] C.D. Versteylen, N.H. van Dijk, M.H.F. Sluiter, First-principles analysis of solute diffusion in dilute bcc Fe-X alloys, Phys. Rev. B 96 (2017), 094105.

[26] H. Fang, C.D. Versteylen, S. Zhang, Y. Yang, P. Cloetens, D. Ngan-Tillard, E. Brück, S. van der Zwaag, N.H. van Dijk, Autonomous filling of creep cavities in Fe-Au alloys studied by synchrotron X-ray nano-tomography, Acta Mater. 121 (2016) 352-364.

[27] J.C. da Silva, A. Pacureanu, Y. Yang, F. Fus, M. Hubert, L. Bloch, M. Salome, S. Bohic, P. Cloentens, High-energy cryo X-ray nano-imaging at the ID16A beamline of ESRF, in: Proc. SPIE 10389, X-Ray Nanoimaging: Instruments and Methods, vol. III, 2017, p. 103890F.

[28] J.C. da Silva, A. Pacureanu, Y. Yang, S. Bohic, C. Morawe, R. Barrett, P. Cloentens, Efficient concentration of high-energy X-rays for diffractionlimited imaging resolution, Optica 4 (2017) 492-495.

[29] C. Gramaccioni, Y. Yang, A. Procopio, A. Pacureanu, S. Bohic, E. Malucelli, S. Lotti, G. Farruggia, I. Bukreeva, A. Notargiacomo, M. Fratini, P. Valenti, L. Rosa, F. Berlutti, P. Cloetens, S. Lagomarsino, Nanoscale quantification of intracellular element concentration by X-ray fluorescence microscopy combined with X-ray phase contrast nanotomography, Appl. Phys. Lett. 112 (2018), 053701.

[30] P. Cloetens, W. Ludwig, J. Baruchel, D. van Dyck, J. van Landuyt, J.P. Guigay, M. Schlenker, Holotomography: quantitative phase tomography with micrometer resolution using hard synchrotron radiation X rays, Appl. Phys. Lett. 75 (1999) 2912-2914.

[31] A. Mirone, B. Brun, E. Gouillart, P. Tafforeau, J. Kieffer, The PyHST2 hybrid distributed code for high speed tomographic reconstruction with iterative reconstruction and a priori knowledge capabilities, Nucl. Instrum. Methods B 324 (2014) 41-48.

[32] http://www.diplib.org/.

[33] M.E. Kassner, T.A. Hayes, Creep cavitation in metals, Int. J. Plast. 19 (2003) $1715-1748$.

[34] R. Raj, M.F. Ashby, Intergranular fracture at elevated temperature, Acta Metall. 23 (1975) 653-666.

[35] A. Pyzalla, B. Camin, T. Buslaps, M. Di Michiel, H. Kaminski, A. Kottar, A. Pernack, W. Reimers, Simultaneous tomography and diffraction analysis of creep damage, Science 308 (2005) 92-95.

[36] A. Isaac, K. Dzieciol, F. Sket, A. Borbély, In-situ microtomographic characterization of single-cavity growth during high-temperature creep of leaded brass, Metall. Mater. Trans. 42 (2011) 3022-3030.

[37] A. Isaac, F. Sket, W. Reimers, B. Camin, G. Sauthoff, A.R. Pyzalla, In situ 3D 
quantification of the evolution of creep cavity size, shape, and spatial orientation using synchrotron X-ray tomography, Mater. Sci. Eng., A 478 (2008) $108-118$.

[38] H.B. Aaron, H.I. Aaronson, Growth of grain boundary precipitates in $\mathrm{Al}-4 \% \mathrm{Cu}$ by interfacial diffusion, Acta Metall. 16 (1968) 789-798.

[39] C.D. Versteylen, N.K. Szymański, M.H.F. Sluiter, N.H. van Dijk, Finite element modelling of creep cavity filling by solute diffusion, Philos. Mag. A 98 (2018) 864-877.

[40] C.D. Versteylen, M.H.F. Sluiter, N.H. van Dijk, Modelling the formation and self- healing of creep damage in iron-based alloys, J. Mater. Sci. 53 (2018) $14758-14773$. 